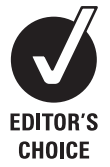

${ }^{1}$ South Essex Partnership NHS Trust, The Taylor Centre, Southend on Sea, Essex, UK; ${ }^{2}$ South Essex Partnership NHS Trust, Runwell Hospital, Wickford, Essex, UK; ${ }^{3}$ The Taylor Centre, Southend on Sea, Essex, UK

Correspondence to:

Dr Jason Luty, South Essex Partnership NHS Trust, The Taylor Centre, Queensway House, Essex Street, Southend on Sea, Essex SS1 2RB, UK; sl006h3607@blueyonder.co.uk

Received 18 July 2008 Revised 9 October 2008 Accepted 30 October 2008

\title{
Preferential publication of editorial board members in medical specialty journals
}

\author{
J Luty, ${ }^{1}$ S M R Arokiadass, ${ }^{2}$ J M Easow, ${ }^{3}$ J R Anapreddy ${ }^{2}$
}

\section{ABSTRACT}

Background: Publication bias and discrimination are increasingly recognised in medicine. A survey was conducted to determine if medical journals were more likely to publish research reports from members of their own than a rival journal's editorial board.

Methods: A retrospective review was conducted of all research reports published in 2006 in the four competing medical journals within five medical specialties. Only three journals were willing to divulge the authorship of reports that had been rejected.

Results: Overall, 4460 research reports were published in 2006 by the 20 journals from five subspecialties (mean $223(S D=164)$ reports per journal; median 176; interquartile range 108-238). On average, 17.2 (7.7\%) reports were from a journal's own editorial board $(S D=10.7$; median 15 ; interquartile range 10-23; $n=20)$, and $6.3(2.8 \%)$ reports were from a member of the editorial board of one of the three rival journals within the specialty $(S D=7.3$; median 3.5 ; interquartile range $1-8 ; n=60)$. There was a statistically significant excess of publications from the journal's own editorial board in 14 of the 20 journals $(p<0.05)$. Journals were almost three times more likely to publish reports from their own editorial board than from one of the three rivals within their subspecialty $(p<0.0001$; median difference 11; MannWhitney U test; power for $5 \%$ significance $>99.99 \%$ ).

Conclusions: There was a significant excess of publications from medical journals' own editorial boards, although it is not possible to determine whether this is due to bias in the peer review process or selective submission by editors.

One former editor of the $B M J$ has claimed that "the whole business of medical journals is corrupt" and "prone to bias". ${ }^{1}$ This bias can take several forms. Traditionally, "publication bias" is a widely recognised phenomenon whereby positive results have an increased likelihood of being published and are published in more influential journals. ${ }^{2-4}$ Publication bias distorts conclusions of metaanalysis and leads to a misleading impression of the effectiveness of some treatments. ${ }^{56}$ A widely reported example of bias is the tendency for research that is funded by pharmaceutical companies to show the company's product in a more favourable light than independently funded trials. ${ }^{7-10}$ There is also widespread condemnation of the distortion of published medical research by the tobacco and alcohol industries. ${ }^{11}{ }^{12}$ Governments have even been implicated in attempts to suppress the results of politically embarrassing medical research or editorials. ${ }^{13}{ }^{14}$ There are also increasing reports of "ghost" authorship that may conceal conflicting interests. ${ }^{15}$
There are few allegations of favouritism by medical journal editors and editorial boards. Nevertheless, editorial bias against mental health researchers from less developed countries has been reported. ${ }^{16}{ }^{17}$ At least one report has suggested that general psychiatry journals are selectively underreporting articles on eating disorders. ${ }^{18}$ There are also occasional references to "hostile reviewers". ${ }^{12}$ These criticisms are widely acknowledged in a recent survey of over 3040 academics worldwide, in which $71 \%$ supported the use of double-blind peer review. ${ }^{19}$

Anecdotal evidence suggested to us that researchers who were on an editorial board had an increased likelihood of having their research published in their own journal. Such a practice would be grossly unethical, particularly as funding for medical research often depends on the capacity of researchers to publish in "high-impact" journals. Consequently, we conducted a survey to determine whether specialised medical journals were more likely to publish research reports from members of their own editorial board than from the members of a rival journal's editorial board.

\section{METHODS}

A retrospective review was conducted of all databased original research reports published in 2006 in the four competing medical journals within five medical specialties: surgery, paediatrics, general practice, psychiatry, and obstetrics and gynaeology. Journals were identified using the 2005 ISI impact factors. ${ }^{20}$ For convenience, the broadest five medical specialties were used that had at least four major medical journals with a closely related subject area. (Unfortunately, "general medicine" itself is divided into several subdisciplines (eg, cardiology, neurology), and these could not reasonably be assessed.) Within each of the five groups, we determined the number of reports that cited as author a member of the editorial board (or editorial advisory board) of any of the four journals within that group. Each of the journals reported a strict ethical code of practice, although none of them anonymised papers prior to peer review.

Odds ratios were calculated with Fisher's exact correction (two-sided) where appropriate. Statistical tests were performed using the StatsDirect Statistical Software program (version 2.4.3). A small minority of editors (18) were represented on two or more editorial boards. When this occurred, the report was counted twice- - under each board where an author was an editor. This small number does not alter the statistical analysis. 
Table 1 Proportion of original research reports from the leading medical journals who cited members of the editorial board as authors in 2006.

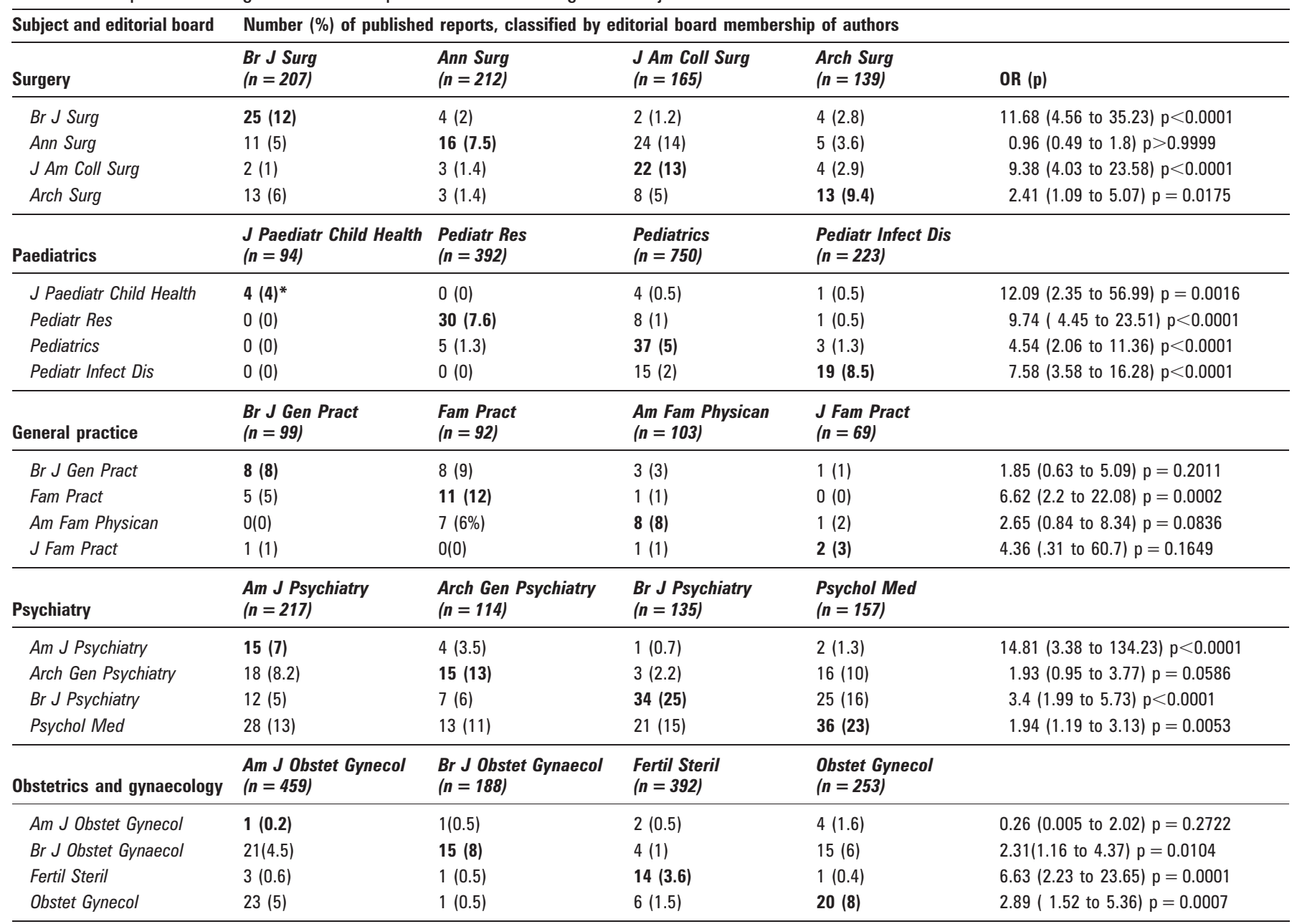

Journal titles are abbreviated as in Index Medicus.

*Bold type indicates the values for research reports by members of the journal's own editorial board.

n, number of research reports; OR, calculated as odds of research report published from journal's own editorial board/odds of research report published from rival journal's editorial board; $p$, statistical significance (Fisher exact test, 95\% confidence interval with two sided test).

\section{RESULTS}

The results are shown in table 1 . Overall there were 4460 research reports published in 2006 by the 20 journals from the five medical subspecialties (mean $223(\mathrm{SD}=164)$ reports per journal; median 176; interquartile range 108-238). On average, $17.2(7.7 \%)$ reports were from each journal's own editorial board $(\mathrm{SD}=10.7$; median 15 ; interquartile range $10-23 ; \mathrm{n}=20)$. On average, $6.3(2.8 \%)$ reports were from one of the three rival journals' editorial boards within the specialty $(\mathrm{SD}=7.3$; median 3.5 ; interquartile range $1-8 ; \mathrm{n}=60$ ). There was a statistically significant excess of publications from the journal's own editorial board in 14 of the 20 journals $(p<0.05)$. Journals were almost three times more likely to publish reports from their own editorial board than from one of the three rivals within their subspecialty $(\mathrm{p}<0.0001$; median difference 11; MannWhitney U test; power for 5\% significance $>99.99 \%$ ).

Between the specialties, primary-care journals had the least significant tendency to publish articles from their own editorial board, with only one journal having a statistically significant rate. By contrast, psychiatry journals tended to publish the highest rate of articles from the journal's own editorial board (two of the four journals had rates exceeding 15\% of reports from members of each journal's own editorial board).

\section{DISCUSSION AND CONCLUSIONS}

This study shows a statistically significant preference among leading medical journals to publish reports that cite authors from their own (rather than a rival journal's) editorial board. It is possible that the results were due to a selective tendency for the editors to preferentially submit their research reports to their own journal; this may be due to authors' sense of loyalty or gratitude to the editors in chief, or to the expectation of a more sympathetic review from their colleagues on the editorial board. Whether this "selective submission" fully explains the fact that the journals were almost three times more likely to receive an article from a member of their own editorial board than from a member of the editorial board of a rival journal begins to stretch belief. Overall, the editorial board for each of the four journals within each specialty are likely to contain equally competent and productive researchers. Each of the journals had similar impact factors within their field. This raises the possibility that editorial procedures are selectively biased in favour of members of their own editorial board.

This report raises a significant ethical question. It is perfectly valid to suggest that the results are due to selective favouritism and bias towards members of a journal's editorial board. To exclude this possibility, we need access to the authorship of the 
reports that were rejected by the various medical journals. The editors of these journals will not release this information. There are two options: first, suppress this report, in which case any abuses of the editorial process will continue; alternatively, publish the report in its current speculative state and challenge the journals to demonstrate that they are keeping a fair and orderly house.

Unfortunately, one of the first responses to bias and discrimination is to deny that it exists at all, and the first step in correcting this is to raise the spectre in public. It is perfectly within the capacity of journal editors to demonstrate that there is no editorial favoritism within their own organisitions, although we were unable to persuade them to do this. For example, the editors in chief of all 20 journals were contacted by post on two occasions in spring 2008 by the authors and a Member of Parliament. Only three journals were amenable to releasing the information on the authorship of rejected articles. This obstruction to the attempts to investigate potential favoritism is a major ethical issue and justifies publication of the results in their current, speculative form. The onus is now on the journals to demonstrate the reputability of the editorial process.

It is widely held that members of editorial boards are encouraged to submit to their own journal. This raises the obvious question, exactly how are editors "encouraged" to submit to their own boards? Editorial board members are mainly unpaid, and the implication that their articles would have enhanced publication rates would be a major incentive both to submit reports as authors and to act as editorial board members.

One defence against the charge of editorial favouritism involves the argument that if journals were publishing inferior research from their own editorial board, then the impact factor of the journal would fall. In fact, a journal's impact factor is dependent on a handful of highly cited reports. ${ }^{1}$ Most published reports in medical journals have a negligible effect on their citation factors.

Funding for medical research depends on either industrial sponsorship, which has been the subject of increasing concern, or national funding bodies such as the UK Medical Research Council and the Wellcome Trust. ${ }^{7}$ Many of these organisations base funding decisions on the publication record of the individual researchers. ${ }^{21}$ Research funding is more likely for authors of articles published in "high-impact" journals. ${ }^{22}{ }^{23} \mathrm{~A}$ fair and transparent system of peer review is therefore an ethical prerequisite. ${ }^{11} 2425$ Unfortunately, all codes of practice among medical editors are entirely voluntary. ${ }^{23}$ Moreover, the guidelines drawn up by the International Committee of Medical Journal Editors and other bodies are often dismissed as ineffective and they lack sufficient endorsement outside the largest journals. ${ }^{15}$ The only practical ways of preventing editorial favouritism is open or double-blind peer review, and even these methods may fail or be perverted (eg, by making reference in the text to "previous research by the authors"). ${ }^{19}$ However, medical journals should make all reasonable efforts to prevent bias and it is hard to justify any valid argument against open or double-blind peer review other than preservation of the status quo.

Funding: The research was funded entirely by the authors. One author (JL) received a free donation of Escitalopram from the manufacturers for a randomised controlled trial of antidepressants in depressed alcoholics. The company provided no other support. The authors have no financial or other association with any commercial company including any pharmaceutical company, the alcoholic drinks industry or any association with the Portman Group, nor have they ever had any such association. The authors are not, nor have ever been, members of the editorial board of any journal.

Competing interests: None.

\section{REFERENCES}

1. Smith R. The trouble with medical journals. London: Pavilion Press, 2006

2. Chalmers I. Underreporting research is scientific misconduct. JAMA 1990;263:1405-8.

3. Easterbrook PJ, Berlin JA, Gopalan R, Matthews DR. Publication bias in clinical research. Lancet 1991;337:867-72.

4. Lee K, Bacchetti P, Sim I. Publication of clinical trials supporting successful new drug applications: a literature analysis. PLoS Med 2008;5(9):e191. http://medicine. plosjournals.org/perlserv/?request $=$ get-document\&doi $=10.1371 /$ journal.pmed 0050191 (accessed 16 December 2008).

5. Egger M, Smith GD. Misleading meta-analysis. BMJ 1995;310:752-4

6. Kirsh I, Deacon BJ, Huedo-Medina TB, et al. Initial severity and antidepressant benefits: a meta-analysis of data submitted to the Food and Drug Administration. PLoS Med 5(2):e45 doi:10.1371/journal.pmed.0050045. http://medicine.plosjournals. org/perlserv/?request $=$ get-documentgdoi $=10.1371 /$ journal.pmed.0050045 (accessed 16 December 2008).

7. Bekelman JE, Li Y, Gross CP. Scope and impact of financial conflicts of interest in biomedical research: a systematic review. JAMA 2003;289:454.

8. Jorgensen AW, Hilden J, Gotzsche PC. Cochrane reviews compared with industry supported meta-analysis and other meta-analyses of the same drugs. BMJ 2006;333:782-5.

9. Epstein R. Influence of pharmaceutical funding on the conclusions of meta-analysis. BMJ 2007;335:1167.

10. Yank V, Rennie D, Bero LA. Financial ties and concordance between results and conclusions in meta-analyses: retrospective cohort study. BMJ 2007;335:1202-5.

11. Babor TF. Diageo, University College Dublin and the integrity of alcohol science: it's time to draw the line between public health and public relations. Addiction 2006;101:1375-7.

12. Hall W. Ensuring that addiction science is deserving of public trust. Addiction 2006;101:1223-4.

13. Hoey JCC, Elmslie T, Flegel KM, et al. Science, sex and semantics: the firing of George Lundberg. CMAJ 1999;160:507-8.

14. Miller $\mathbf{P}$, Moore D, Strang J. The regulation of research by funding bodies. Int J Drug Policy 2006;17:12-6.

15. Hargreaves $\mathbf{S}$. Industry funded trials often have ghost authorship. BMJ 2007;334:223.

16. Patel V, Sumathipala A. International representation in psychiatric literature: survey of six leading journals. Br J Psychiatry 2001:178:406-9.

17. Patel V, Kim Y. Contribution of low- and middle-income countries to research published in leading general psychiatry journals, 2002-2004. Br J Psychiatry 2007; 190:77-8

18. Frost S, Murphy R, Webster P, Schmidt U. Are top journals biased against eating disorders topics? Am J Psychiatry 2003:160:363-5.

19. Kmietowicz Z. Double blind peer reviews are fairer and more objective, say academics. BMJ 2008;336:241.

20. Institute for Scientific Information. Journal citation reports. Chicago: Thomson Reuters, 2008. http://www.thomsonreuters.com/products_services/scientific/ Journal Citation Reports (accessed 22 December 2008).

21. Hobbs FD, Stewart PM. How should we rate research? BMJ 2006;332:983-4.

22. Lexchin J, Light DW. Commercial influence and the content of medical journals. BMJ 2006;332:1444-7.

23. Tamber PS. The trouble with medical journals by Richard Smith: an alternative view. BMJ 2007; 334:125

24. Edwards G, West R, Babor TF, et al. An invitation to an alcohol industry lobby to help decide public funding of alcohol research and professional training: a decision that should be reversed. Addiction 2004;99:1235-6.

25. Altman DG. Endorsement of the CONSORT statement by high impact medical journals: survey of instructions for authors. BMJ 2005;330:1056-7. 